TURIZAM

Volume 23, Issue 2

100-106 (2019)

ORIGINAL

SCIENTIFIC PAPER

\section{Language-specific Differences in Online Reviews - Case of Fine-dining Prague Restaurants}

\author{
Zuzana Kvitkova ${ }^{\mathrm{A}}$
}

Received: May 2019 | Accepted: July 2019

DOI: 10.5937/turizam23-21570

\begin{abstract}
Word-of-mouth is an important factor in all phases of the purchase decision-making process. As the web 2.0 came in, online reviews platforms grew up and started significantly influencing the travel behavior in the last years, including gastronomy. The largest platform is Tripadvisor.com. With respect to worldwide usage and importance of Tripadvisor.com in the tourism sector, this was chosen as a base for the research of restaurant reviews. This study aims to identify whether there are differences in the satisfaction level with the restaurants between language groups. Prague is the top highlight of the tourism offer of the Czech Republic. The capital is also a leader in regards to quality and luxury services, gastronomy is no exception. According to Tripadvisor.com, there are almost 120 restaurants offering fine dining and most of them offer a good quality according to the reviews. This type of restaurants for the high-end customers was analyzed to identify the most demanding language groups and the less critical language groups. The German, Spain, Italian, French and Czech language were analyzed. With some limitations, we can assign the language to a nationality. The average evaluation for each language is calculated and the statistical tests are made to confirm the findings.
\end{abstract}

Keywords: restaurants, online reviews, language-specific

\title{
Introduction
}

Tourism of nowadays is strongly influenced by the internet and different mobile applications. The behavior of tourists changes as the new possibilities arise. To make the right decision and to choose the best valuable product is one of the most important issues of today's tourists. In this process, the word-of-mouth can help. Word-of-Mouth (WOM) is an informal communication towards customers about usage of particular goods or services or about the sellers (Westbrook, 1987). In tourism we are mostly concerned about services and word-of-mouth has an important influence on decision-making in tourism. Recommendations and reviews of destinations, hotels and restaurants play a role in the whole process, starting with inspiration

A Metropolitan Univesity of Prague, Dubečská 900/10, 10031 Praha, Czech Republic, Corresponding author: zuzana.kvitkova@mup.cz 
and ending with a post-stay evaluation, comparison with other's feelings and impressions and sharing. With the web 2.o, the channels of communication changed; however, the importance of electronic "word-of-mouth" is very high or even higher than the offline WOM has ever been. A term electronic WOM (eWOM) is used for online WOM and the reviews are one of the most powerful eWOM. User-generated reviews can be defined as peer-generated reviews posted on the company's website or third parties' platforms (Mudambi, Schuff, 2010).

The most important platform for reviews is Tripadvisor.com with more than 702 Mio. reviews of 8 million of accommodations, airlines, experiences and restaurants (www.tripadvisor.com). As one of the biggest platforms, the Tripadisor.com is an important source of information and tries to be a reliable partner and is also a leader in online review fraud prevention. The real number of reviews changes every day.

Visitors and their online reviews are the WOM of today. They have the power to influence future visitors' decisions and therefore the companies care about social media and review platforms and create strategies for online reputation management. Most of the managers do their best to satisfy the customers and to get better ratings. The aim of this research is to identify whether all the tourists are equally demanding and will write the same review and give the same rating after being served in the same way. This knowledge could help the companies to identify and pay higher attention to the most demanding groups of customers and increase the online rating. For this paper, the language groups and the Prague fine-dining restaurants were chosen to be analyzed. Language-specific differences in the rating of the fine-dining restaurants will be analyzed based on 10,497 reviews.

\section{Online reviews in tourism and restaurants}

Online review is any positive or negative comment from a potential, actual or former client regarding a product or company that is accessible to many people through the internet (Hennig-Thurau et. al, 2004). It is possible to rate almost any service (including teachers, lawyers or doctors), however, in tourism it is already a standard to use the reviews for decision making and nobody hesitates to write one. O'Reilly a Marx (2011) define three main purposes why to read a review:

1. creating a better image in the community,

2. minimize the risk related to the purchase of (expensive) goods and services and

3. acknowledge the decision to buy a particular product.

It is not possible to try or touch the product of hotels, destinations, restaurants or tour operators in advance. Therefore the client undergoes the risk of buying a low-quality product for a higher price. The decision-making process is even complicated because of the following facts:

1. non-tangible product in return to the money spent,

2. the amount of expenditures in comparison to regular earnings is high,

3. expenditure involves savings and usually, it requires long-term planning and

4. it is not a spontaneous or capricious purchase (Wahab et al., 1976).

The role of reviews as a tool of minimizing the risk is therefore crucial.

Reviews are also an important object of the research. Most of them are dedicated to the hotel industry, e.g. impact of the reviews on sales (Lu et. al., 2014). According to the (Viglia et 
al., 2016) an increase of 1 point in rating led to an increase of $7.5 \%$ in sales. The factors leading to overall satisfaction are also being analyzed ( $\mathrm{Qu}$ et al., 2000). In the restaurant business, online reviews are accepted as expert opinions (Parikh, 2013). The more reviews the restaurant has the higher is the probability of gaining a new customer (Park et al., 2007). The more reviews the restaurant has, the more popular it is supposed to be. This process leads to an increase in sales as well. Anderson and Magruder (2012) measured the impact of increasing rating on Yelp and found out that an increase from 3.5 to 4.0 increased restaurant sales by upwards of $19 \%$. According to Gunden's findings, $62 \%$ of respondents are influenced by online reviews and $55.5 \%$ check the online reviews most of the time or always (Gunden, 2017).

\section{Language-group specifics of rating and reviews}

There are several papers analyzing the language or national specifics of tourists. Tourists with different cultural backgrounds tend to different consumption concepts, different values and priorities and therefore to different ratings (Ayoun, Moreo, 2008). The fact that different cultures have a different behavioral intention was confirmed in (Wen et al., 2012) where the difference between American and Chinese customers of fast-food restaurants were analyzed. Pacheco (2016) analyzed the relationship between online hotel reviews and five different language groups and nationalities and found a significant difference in behavior of Spanish guests, especially in lower-class hotels. In (Liu et al., 2017) the language-specific drivers of satisfaction of hotel guests from different countries were researched and the authors found out a substantial difference in the role of various hotel attributes for each language group. In some cases, the language is assigned to a nationality (Pacheco, 2016), in some researches the nationality is not important and the results are analyzed on the level of culture (individualistic or collectivistic) (Wen et al., 2012), some of the papers leave the results on the level of language.

\section{Methodology and data}

For this research, a method of web scraping was used. The scraping and data downloading were processed on the 28 th of September 2018 . The collected data were manually checked and corrected in case of any problem. Together 42,422 reviews were collected and from these, the selected languages were analyzed - together 10,497 reviews, for more details see Table 1 . The languages for analysis were chosen according to the tourism statistics in Prague - from the top 10 source countries for tourism in Prague.

The criteria for adding a language to the research were the following:

1. Latin alphabet (therefore the South Korean, Chinese and Russian are not included),

2. enough reviews in that language in the fine-dining restaurant (excludes Slovakia) and

3. possibility to assign the language to a nationality (therefore the English reviews cannot be analyzed, as there are not only tourists from Great Britain and the USA, but also different tourist from other countries who do not write the review in their native language).

After applying these criteria, the following languages were analyzed: German (11.6\% of tourists), Italian (5.1\%), Spanish (3.4\%), French (3.3\%) and Czech (10.7 \%).

As a subject of the research, the fine-dining restaurants were selected - as the representatives of high-end services for the most demanding clients. On Tripadvisor.com there were 
found 120 restaurants tagged as fine-dining restaurants in Prague. The minimum number of reviews was set to 100 and the minimum for each language to 5 . After applying these limits 40 restaurants were considered for the research with a minimum of 200 reviews in all languages together.

Table 1. Number of reviews in each language

\begin{tabular}{|c|c|}
\hline Language & Number of reviews \\
\hline All & 42,422 \\
\hline French & 2,841 \\
\hline Italian & 2,466 \\
\hline Czech & 2,181 \\
\hline German & 1,729 \\
\hline Spanish & 1,280 \\
\hline
\end{tabular}

Source: own data analysis

The most reviews are in the English $(25,881)$, however, English is not the subject of the research. The next language is French, followed by Italian and Czech. Least reviews are in Spanish. If we compare the number of reviews with the number of tourists in Prague, we can see, that there is a significant difference in the relative representation of French tourist and French reviews. It would be interesting to investigate whether the French tourists visit more often the restaurants or whether they are more active in writing the reviews. With German tourists and German reviews, an opposite situation is observed.

The data were first analyzed with simple statistical characteristics - mean and standard deviation, for details, see Table 2 . The first results indicate a difference in the ratings among the different language groups. The statistical T-test is used to confirm the differences, see Table 3. Each language is compared with the data set collected as "All languages".

\section{Results and discussion}

The downloaded data were first analyzed with means and standard deviations. This analysis is shown in the following table.

Table 2. Average rating in each language

\begin{tabular}{|c|c|c|}
\hline Language & Average rating & Standard deviation \\
\hline Italian & 4.134 & 0.278 \\
\hline Spanish & 4.301 & 0.357 \\
\hline French & 4.348 & 0.354 \\
\hline German & 4.45 & 0.277 \\
\hline All & 4.488 & 0.226 \\
\hline Czech & 4.645 & 0.294 \\
\hline
\end{tabular}

Source: own data analysis

According to the average rating the Italian, Spanish and French guests are the most demanding and it is difficult to satisfy them. The German guests are average demanding and 
the Czech guests are the most tolerant customers. Spanish and French guests have the highest standard deviation; this can indicate a higher diversity of difficulty level in these language groups. The statistical significance of the language-specific differences will be tested with twotier pair t-test at mean value. The t-test is comparing the particular language group with all reviews that represent a set of 42,422 reviews.

Table 3. T-test results for the languages

\begin{tabular}{|c|c|c|c|c|c|}
\hline \multirow{2}{*}{} & \multicolumn{5}{|c|}{ T-test results for each language } \\
\cline { 2 - 6 } & Czech & German & Italian & Spanish & French \\
\hline $\mathrm{t}$ Stat & -3.745 & 1.053 & 3.923 & 3.680 & 3.285 \\
\hline $\mathrm{P}(\mathrm{T}<=\mathrm{t})(1)$ & 0.000 & 0.149 & 0.000 & 0.000 & 0.001 \\
\hline $\mathrm{t}$ crit (1) & 1.685 & 1.685 & 1.685 & 1.685 & 1.685 \\
\hline $\mathrm{P}(\mathrm{T}<=\mathrm{t})(2)$ & 0.001 & 0.299 & 0.000 & 0.001 & 0.002 \\
\hline $\mathrm{t}$ crit (2) & 2.023 & 2.023 & 2.023 & 2.023 & 2.023 \\
\hline
\end{tabular}

Source: own data analysis

The t-test confirmed differences for some language groups at the 0.05 level and on the 0.01 level as well. The statistically significant difference was confirmed for Italian, Spanish and French language groups. These language groups are substantially more demanding and more difficult customers than average. The statistical significance was confirmed for the Czech speaking customers as well, however, in an opposite scale - they are substantially more tolerant and more satisfied with the supplied service and food. The only language group that is satisfied on an average level is the group of German-speaking customers, where no significant difference was found.

The research confirms the findings of the previous authors, that the cultural and national determinants are important for the satisfaction level. This paper, presenting research of fine-dining restaurants in Prague interestingly correlates with findings in (Pacheco, 2016), where the Spanish tourists are also identified as one of the most demanding customers in the hotel business of Porto.

In the case of this paper, it would be possible to assign the language to nationality with some limitations. German-speaking tourists are not only from Germany but from Austria as well, the Spanish language is used in other countries etc. However, the dominance of the main countries - Germany, Spain, France - as source countries for Prague is so prevailing that it would be possible to undergo the risk of having guests from Switzerland or South America in the sample without influencing the results in a significant measure. As future research, it would be interesting to compare the results with Hofstede's cultural dimensions. After the language specifics have been identified, the differences in the importance of each component of the satisfaction could be analyzed. For this purpose, more restaurants should be considered (not only fine dining) to get a wider range of ratings as most of the fine-dining restaurants have the evaluation of the factors 4.5 or 5.0 and more detailed information is on Tripadvisor.com not accessible. It would be also useful to add some other languages - eg. Chinese, Russian - in future research. 


\section{Conclusion}

The aim of this paper was to identify whether there are some differences in language groups in regards to evaluating the experience and rating the high-end restaurants. From the literature review, it was evident that the reviews in tourism and restaurant business play an important role in the decision-making process and that we could expect also some differences between the language groups. As a research sample, the ratings of Prague fine-dining restaurants on Tripadvisor.com were chosen. In this type of restaurants, we expect the most demanding customers and the most critical attitude. According to the statistics of Prague visitors the important language groups were selected and after application of the requirements these languages were analyzed: Czech, German, Spanish, Italian and French. After application of the limits for restaurants (more than 100 reviews, minimum 5 reviews in each language) 40 restaurants stayed in the research together with 42,422 reviews and 10,497 reviews in the analyzed languages. After a simple statistical analysis, the first results could be observed and the statistical t-tests confirmed the significant differences for Italian, Spanish and French language as the most demanding language groups. A statistical significance was confirmed also for the Czech language, however in an opposite scale - as the most tolerant language group in the research. For future research, a more detailed analysis of each satisfaction component for the different language groups could be considered.

\section{Acknowledgements}

This study is the result of Metropolitan University Prague research project no. 68-02 "Territorial studies, Economy and International Relations" (2019) based on a grant from the Institutional Fund for the Long-term Strategic Development of Research Organizations. Some parts of the paper have been presented at the 2nd International Scientific Conference on IT, Tourism, Economics, Management and Agriculture - ITEMA 2018.

\section{References}

Anderson, M., Magruder, J. 2012. Learning from the crowd: Regression discontinuity estimates of the effects of an online review database. The Economic Journal 122(563), 957-989. doi:10.1111/j.1468-0297.2012.02512.X

Ayoun, B., Moreo, P. 2008. Does national culture affect hotel managers' approach to business strategy. International Journal of Contemporary Hospitality Management 32(1), 52-65

Gunden, N. (2017). How Online Reviews Influence Consumer Restaurant Selection. Graduate Theses and Dissertations.

Hennig-Thurau, T., Gwinner, K. P., Walsch, G., Gremler, D. D. 2004. Electronic Word-OfMouth via Consumer-Opinion Platforms: What Motivates Consumers to Articulate Themselves on the Internet? Journal of Interactive Marketing 18(1), 38-52. Available at: https://doi.org/10.1002/dir.10073

Liu, Y., Teichert, T., Rossi, M., Li, H., Hu, F. 2017. Big data for big insights: Investigating language-specific drivers of hotel satisfaction with 412,784 user-generated reviews. Tourism Management 59, 554-563. 
Lu, Q., Ye, Q., Law, R. 2014. Moderating effects of product heterogeneity between online wordof-mouth and hotel sales. Journal of Electronic Commerce Research 15(1), 1-12.

Mudambi, S. M., Schuff, D. 2010. Research Note: What Makes a Helpful Online Review? A Study of Customer Reviews on Amazon.com, MIS Quarterly 34/, 185-200.

O’Reilly, K., Marx, S. 2011. How young, technical consumers assess online WOM credibility. Qualitative Market Research 14(4), 330-359.

Pacheco L. 2016. An analysis of online reviews by language groups: the case of hotels in Porto, Portugal. European Journal of Tourism Research 14, 66-74

Parikh, A. A. (2013). User generated restaurant reviews: Examining influence and motivations for usage (Doctoral dissertation, Purdue University). Retrieved from https://search.proquest.com/docview/1476207537?accountid $=14745$

Park, D. H., Lee, J., Han, I. 2007. The effect of on-line consumer reviews on consumer purchasing intention: The moderating role of involvement. International journal of electronic commerce 11(4), 125-148.

Qu, H., Ryan, B., Chu, R. 200o. The importance of hotel attributes in contributing to travelers' satisfaction in the Hong Kong hotel industry. Journal of Quality Assurance in Hospitality $\mathcal{E}$ Tourism 1(3).

Viglia, G., Minazzi, R., Buhalis, D. 2016. The Influence of E-Word-Of-Mouth on Hotel Occupancy Rate [online]. International Journal of Contemporary Hospitality Management 28(9), 2035-2051.

Wahab, S., Crampon, L.G., Rothfield, L.M. (1976). Tourism Marketing. London, England: Tourism International Press.

Wen, Ch., Qin, H., Prybutok, V. R., Blankson, Ch. 2012. The Role of National Culture on Relationships Between Customers' Perception of Quality, Values, Satisfaction, and Behavioral Intentions. Faculty Research \& Creative Activity, 9.

Westbrook, R. A. 1987. Product/consumption-based affective responses and postpurchase processes. Journal of Marketing Research 24(3), 258-270.

Internet 1: https://tripadvisor.mediaroom.com/cz-about-us. (10.11.2019.) 